\title{
DIAGNOSA PENYAKIT DIABETES DENGAN METODE FORWARD CHAINING
}

\author{
Sri Hardani \\ Sistem Informasi \\ Universitas Bina Sarana Informatika \\ http://www.bsi.ac.id/ \\ sri.sin@bsi.ac.id
}

\begin{abstract}
Diabetes is a disease that causes many deaths. From year to year the number of people with diabetes is increasing. If known earlier, sufferers can control their disease through medication, lifestyle changes, and eating patterns. With the technology that helps in diagnosing the disease, will help patients to find out the disease without having to see a doctor. By applying the forward chaining method that works by reading the facts that are then applied in the applicable rules, so as to produce a conclusion, the system reads the symptoms complained of by the patient to find out the type of diabetes suffered.
\end{abstract}

Keywords: expert system, diagnosis, diabetes, inference engine, forward chaining.

Intisari-Penyakit diabetes merupakan salah satu penyakit yang mengakibatkan banyak kematian. Dari tahun ke tahun jumlah penderita penyakit diabetes semakin meningkat. Jika dikatahui lebih awal, penderita dapat mengendalikan penyakitnya baik melalui pengobatan, perubahan gaya hidup, dan pola makan. Dengan adanya teknologi yang membantu dalam mendiagnosa penyakit, akan membantu pasien untuk mengetahui penyakitnya tanpa harus ke dokter. Dengan menerapkan metode forward chaining yang bekerja dengan membaca fakta-fakta yang ada kemudian diterapkan dalam rule yang berlaku, sehingga menghasilkan sebuah kesimpulan, sistem membaca gejala-gejala yang dikeluhkan pasien untuk mengetahui jenis penyakit diabetes yang diderita.

Kata Kunci: sistem pakar, diagnosa, diabetes, inference engine, forward chaining.

\section{PENDAHULUAN}

Diabetes melitus merupakan penyakit gangguan metabolitik menahun akibat pancreas tidak memproduksi cukup insulin atau tubuh tidak dapat menghasilkan insulin yang diproduksi secara efektif, sehingga terjadi peningkatan konsentrasi glukosa di dalam darah (hiperglikemia)(Kementrian Kesehatan, 2014).
Secara global, jumlah penderita diabetes mengalami peningkatan signifikan dari tahun ke tahun. Diabetes Atlas edisi ke-8 yang diterbitkan oleh Federasi Diabetes Internasional 2017 menyatakan bahwa 425 juta dari total populasi seluruh dunia, atau sekitar 8,8 persen orang dewasa berumur 20-79 tahun merupakan penderita diabetes. Tahun 2017 Indonesia menempati urutan ke-2 sebagai negara dengan jumlah penderita diabetes diantara negara-negara asia pasifik. Dengan jumlah penderita diabetes sebanyak 10.578.401(Cho et al., 2018).

Top 5 countries for number of people with diabetes [18-99 years), 2017

\begin{tabular}{lr} 
1.China & $120,907,995$ \\
\hline 2.Indonesia & $10,578,401$ \\
\hline 3.Japan & $8,343,288$ \\
\hline 4.Thailand & $4,426,959$ \\
\hline 5.Philippines & $3,878,747$ \\
\hline
\end{tabular}

Sumber: (Cho et al, 2018)(Cho et al., 2018)

Gambar1. Negara Dengan Jumlah Prevelensi

Diabetes Terbanyak Di Kawasan Asia Pasifik

Peningkatan jumlah prevelensi diabetes di negara berkembang diakibatkan gaya hidup dimana masyarakat kurang memperhatikan asupan makanan dan kurangnya aktifitas fisik. Dalam jangka panjang, penyakit diabetes yang tidak ditangani secara tepat, dapat mengakibatkan berbagai komplikasi pada bagian tubuh lain. Komplikasi yang muncul antara lain gangguan penglihatan bahkan dapat mengakibatkan kebutaan, luka yang susah disembuhkan, penyakit jantung, ginjal, hipertensi, dan stroke(Choubey \& Paul, 2017).

Diabetes merupakan salah satu penyebab utama dari kematian akibat penyakit tidak menular(Susanti \& Bistara, 2018). Deteksi dini pada penderita diabetes dapat membantu penderita mengetahui lebih awal penyakit yang dideritanya, sehingga penderita dapat mengontrol melalui suntik insulin, minum obat, menjaga pola 
makan, dan program latihan untuk aktifitas fisik (Choubey \& Paul, 2017).

Saat ini perkembangan teknologi komputer dengan sistem pakar telah menjangkau berbagai bidang, termasuk dunia kesehatan. Salah satu penerapan sistem pakar dalam dunia kesehatan adalah untuk mendiagnosa penyakit. Dengan diagnosa awal, makan dapat diberikan saran kepada pasien apa yang harus dilakukan terkait penyakit yang diderita. Sistem pakar merupakan program komputer yang meniru proses dan penalaran para pakar dalam memecahkan permasalahan tertentu(Zeki, Malakooti, Ataeipoor, \& Tabibi, 2012).

Dalam sistem pakar diagnosa diabetes, mengadopsi pengetahuan para pakar dalam mendiagnosa penyakit diabetes dan mengimplementasikan dalam aplikasi menggunakan metode pengambilan keputusan yang ada dalam ilmu computer. Salah satu metode pengambilan keputusan yang sering digunakan adalah forward chaining. Forward chaining merupakan salah metode mesin inferensi yang melakukan pencarian aturan inferensi sampai ia menemukan suatu kondisi yang bernilai benar(Rupnawar, Jagdale, \& Navsupe, 2016).

\section{BAHAN DAN METODE}

Dalam melakukan penelitian ini, metode yang digunakan adalah sebagai berikut:

1. Pengamatan (Observation)

Pengumpulan data dengan melakukan pengamatan secara langsung pada pasien yang sudah terdiagnosa menderita diabetes.

2. Wawancara (Interview)

Mengunpulkan data hasil wawancara penderita diabetes.

3. Studi Pustaka (Literature Review)

Infromasi tambahan yang diperoleh dengan membaca referensi dari buku-buku dan literature yang berhubungan dengan dengan permasalahan yang dibahas dalam penelitian ini yaitu diagnosa diabetes.

Metode inferensi merupakan kumpulan prosedur yang bertujuan melakukan penalaran(Salisah, Lidya, \& Defit, 2015). Dalam penelitian ini, metode inferensi yang digunakan adalah metode forward chaining. Metode forward chaining bekerja dengan mencari aturan inferensi sampai menemukan kondisi yang bernilai benar. Ketika kondisi tersebut ditemukan maka dapat dibuat sebuah kesimpulan, maka akan menghasilkan informasi baru yang dapat ditambahkan pada data set. Mesin inferensi bekerja dengan menggunakan sekumpulan kondisi dan derivasi sampai akhirnya memberikan keputusan. Dalam pengerjaannya, mesin inferensi mempertimbangkan semua fakta dan aturan, serta memilahnya sebelum menyimpulkan solusi(Rupnawar et al., 2016).

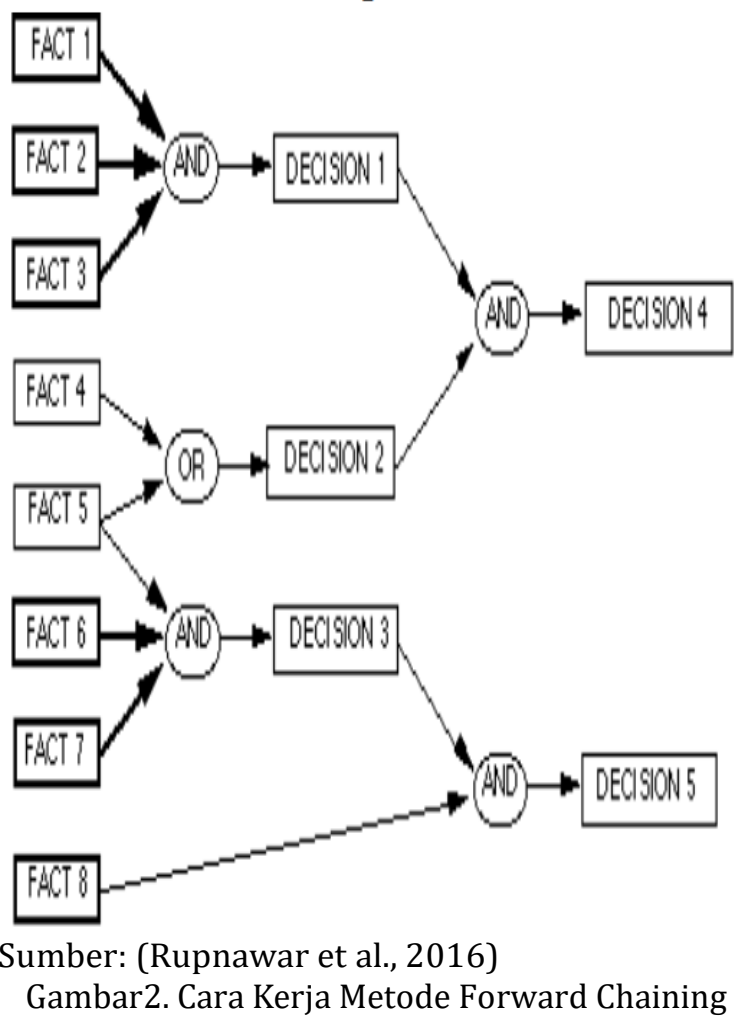

Dalam gambar di atas terdapat sejumlah fakta yang merupakan kondisi yang dialami pasien. Fakta-fakta ini memberikan sejumlah keputusan dan kemudian keputusan-keputusan ini akhirnya memberikan satu hasil. Definisi standar dari sistem forward-chaining adalah bahwa sistem beroperasi dengan mengulangi serangkaian urutan operasi.

\section{HASIL DAN PEMBAHASAN}

Pada bagian ini, dijelaskan hasil penelitian yaitu penerapan metode forward chaining dalam pengembangan aplikasi sistem pakar untuk mendeteksi penyakit diabetes. Dalam sistem pakar ini mengimplementasikan keahlian seorang pakar untuk menghasilkan sebuah kesimpulan.

\section{A. Alur Sistem}

Sistem pakar ini dikembangan dengan model sesin inferensi yaitu forward chaining untuk mendiagnosa penyakit diabetes. Sistem akan menganalisa fakta yang diperoleh dari inputan berdasarkan role yang tersimpan dalam database sistem. Role yang tersimpan dalam database merupakan pengetahuan pakar yang diadopsi ke dalam sistem untuk dapat memberikan 
kesimpulan terhadap fakta yang diiput oleh pengguna. Logika percabangan IF - Then diformulasikan untuk mendiagnosa apakah pasien termasuk dalam kategori diabetes tipe 1, diabetes tipe 2, prediabetes, atau gestational.

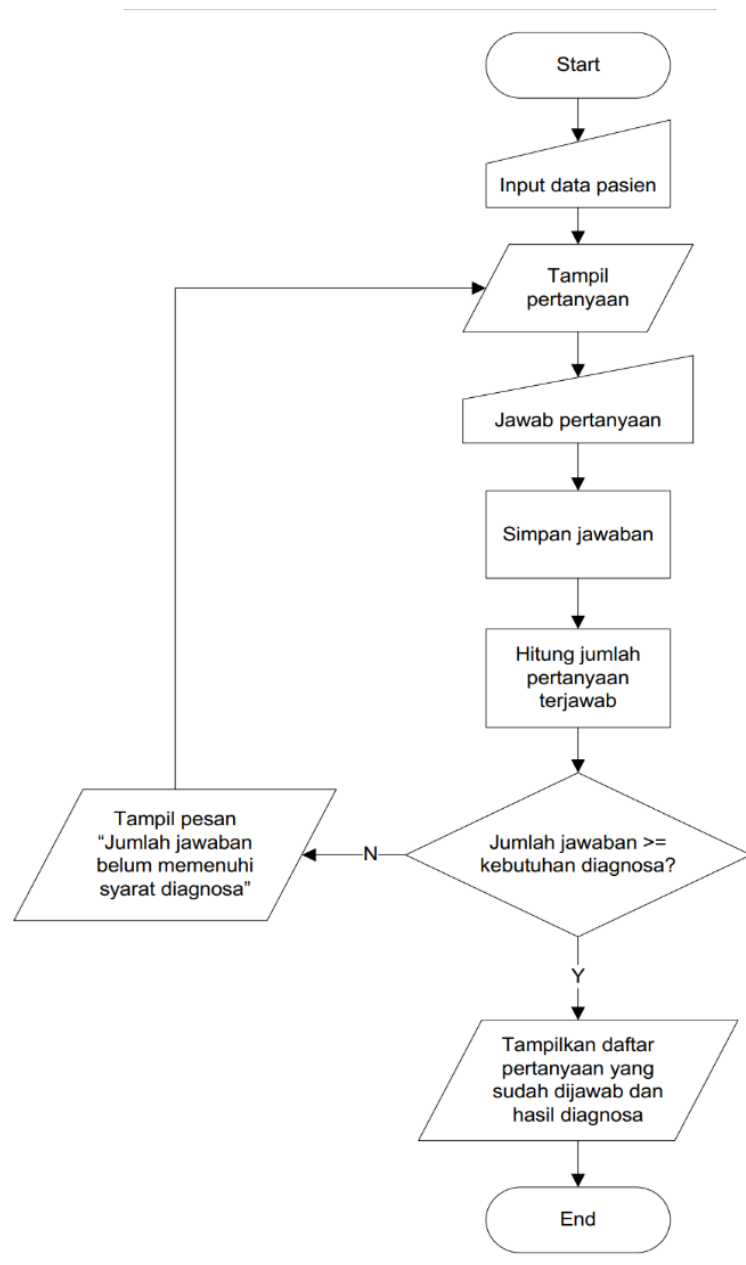

Sumber: (Hardani, 2019)

Gambar 3. Workflow Diagnosa Penyakit Diabetes

Gambar 3 diatas menunjukkan alur aplikasi diagnosa penyakit diabetes. Setelah pengguna menginput data singkat pasien, aplikasi akan menampilkan satu persatu pertanyaan yang berhubungan dengan gejala penyakit diabetes. Pengguna dapat nenampilkan hasil diagnosa tanpa harus menyelesaikan semua pertanyaan. Jika sistem menganggap bahwa jawaban sudah cukup, maka sistem akan menampilkan hasil diagnosa. Jika belum cukup, maka pengguna akan diminta untuk menjawab pertanyaan berikutnya.

\section{B. Knowledge Base}

Tabel 1. Knowledge Base Diagnosa Penyakit Diabetes

\begin{tabular}{ccccc}
\hline Gejala & Tipe 1 & Tipe 2 & Pre diabetes & Gestational \\
\hline G01 & $\sqrt{ }$ & $\sqrt{ }$ & $\sqrt{ }$ & \\
\hline G02 & $\sqrt{ }$ & $\sqrt{ }$ & $\sqrt{ }$ & \\
\hline
\end{tabular}

\begin{tabular}{|c|c|c|c|c|}
\hline Gejala & Tipe 1 & Tipe 2 & Pre diabetes & Gestational \\
\hline G03 & $\sqrt{ }$ & $\sqrt{ }$ & $\sqrt{ }$ & \\
\hline G04 & $\sqrt{ }$ & & & \\
\hline G05 & & $\sqrt{ }$ & $\sqrt{ }$ & $\sqrt{ }$ \\
\hline G06 & & $\sqrt{ }$ & & \\
\hline G07 & & $\sqrt{ }$ & $\sqrt{ }$ & \\
\hline G08 & $\sqrt{ }$ & $\sqrt{ }$ & & \\
\hline G09 & & $\sqrt{ }$ & $\sqrt{ }$ & \\
\hline G10 & & $\sqrt{ }$ & $\sqrt{ }$ & \\
\hline G11 & & & $\sqrt{ }$ & \\
\hline G12 & & & $\sqrt{ }$ & \\
\hline G13 & & & $\sqrt{ }$ & \\
\hline G14 & & & $\sqrt{ }$ & \\
\hline G15 & $\sqrt{ }$ & & & \\
\hline G16 & $\sqrt{ }$ & & & \\
\hline G17 & & $\sqrt{ }$ & & \\
\hline G18 & & & & $\sqrt{ }$ \\
\hline G19 & & & & $\sqrt{ }$ \\
\hline G20 & & & & $\sqrt{ }$ \\
\hline G21 & $\sqrt{ }$ & $\sqrt{ }$ & & \\
\hline G22 & $\sqrt{ }$ & $\sqrt{ }$ & & \\
\hline G23 & $\sqrt{ }$ & $\sqrt{ }$ & & \\
\hline G24 & $\sqrt{ }$ & $\sqrt{ }$ & & \\
\hline G25 & $\sqrt{ }$ & $\sqrt{ }$ & & \\
\hline G26 & $\sqrt{ }$ & & & \\
\hline G27 & $\sqrt{ }$ & & & \\
\hline G28 & $\sqrt{ }$ & & & \\
\hline G29 & $\sqrt{ }$ & & & \\
\hline G30 & & $\sqrt{ }$ & & \\
\hline G31 & & $\sqrt{ }$ & & \\
\hline G32 & & $\sqrt{ }$ & & \\
\hline G33 & $\sqrt{ }$ & $\sqrt{ }$ & & \\
\hline G34 & $\sqrt{ }$ & $\sqrt{ }$ & & \\
\hline G35 & $\sqrt{ }$ & $\sqrt{ }$ & & \\
\hline G36 & $\sqrt{ }$ & $\sqrt{ }$ & & \\
\hline G37 & $\sqrt{ }$ & $\sqrt{ }$ & & \\
\hline G38 & $\sqrt{ }$ & $\sqrt{ }$ & & $\sqrt{ }$ \\
\hline G39 & & $\sqrt{ }$ & & \\
\hline G40 & & & $\sqrt{ }$ & \\
\hline G41 & $\sqrt{ }$ & $\sqrt{ }$ & & \\
\hline G42 & & & & $\sqrt{ }$ \\
\hline G43 & $\sqrt{ }$ & $\sqrt{ }$ & & \\
\hline G44 & $\sqrt{ }$ & $\sqrt{ }$ & & \\
\hline G45 & $\sqrt{ }$ & $\sqrt{ }$ & & \\
\hline G46 & $\sqrt{ }$ & $\sqrt{ }$ & & \\
\hline
\end{tabular}


VOL. 5. NO. 2 FEBRUARI 2020

\begin{tabular}{ccccc}
\hline Gejala & Tipe 1 & Tipe 2 & Pre diabetes & Gestational \\
\hline G47 & $\sqrt{ }$ & $\sqrt{ }$ & \\
\hline G48 & $\sqrt{ }$ & & \\
\hline G49 & $\sqrt{ }$ & $\sqrt{ }$ & \\
\hline G50 & $\sqrt{ }$ & $\sqrt{ }$ & \\
\hline G51 & $\sqrt{ }$ & $\sqrt{ }$ & \\
\hline G52 & & $\sqrt{ }$ & \\
\hline G53 & $\sqrt{ }$ & $\sqrt{ }$ & \\
\hline G54 & $\sqrt{ }$ & $\sqrt{ }$ & \\
\hline G55 & $\sqrt{ }$ & $\sqrt{ }$ & \\
\hline G56 & & & $\sqrt{ }$ \\
\hline G57 & & & $\sqrt{ }$ \\
\hline G58 & & & $\sqrt{ }$ \\
\hline G59 & & & \\
\hline G60 & & & \\
\hline SGmber: (Choubey Paul, 2017)
\end{tabular}

Sumber: (Choubey \& Paul, 2017)

Keterangan hasil diagnosa :

1. Diabetes tipe 1

Diabetes tipe 1 disebut juga diabetes mellitus yang tergantung pada insulin (insulin-dependent diabetes mellitus - IDDM). Diabetes tipe 1 dapat mencapai 5\% hingga 10\% dari semua kasus diabetes yang didiagnosis. Faktor risiko kurang terdefinisi dengan baik untuk diabetes tipe 1 dibanding diabetes tipe 2. Faktor genetik dan lingkungan sangat berhubungan dalam perkembangan diabetes tipe ini.(Zeki et al., 2012)

\section{Diabetes tipe 2}

Diabetes tipe 2 disebut juga diabetes mellitus yang tidak tergantung pada insulin (non-insulindependent diabetes mellitus - NIDDM) atau diabetes yang menyerah orang dewasa. Diabetes tipe 2 dapat mencapai sekitar 90\% hingga 95\% dari semua kasus diabetes yang didiagnosis. Faktor risiko untuk diabetes tipe 2 meliputi usia yang lebih tua, obesitas, riwayat diabetes pada keluarga, riwayat diabetes gestasional, gangguan toleransi glukosa, kurang aktivitas fisik, dan ras / etnis (Zeki et al., 2012)

\section{Pre diabetes}

Prediabetes adalah keadaan hiperglikemia dengan parameter glikemik di atas normal tetapi masih di bawah ambang batas diabetes, artinya tidak cukup tinggi untuk masuk dalam kategori diabetes(Bansal, 2015).

\section{Gestational}

Kasus ini terjadi pada 2\% sampai 5\% dari semua kehamilan, tetapi biasanya akan menghilang ketika kehamilan berakhir. Wanita hamil memiliki cukup insulin, tetapi efek insulin sebagian diblokir oleh berbagai hormon lain yang diproduksi di plasenta. Kondisi ini disebut resistensi insulin.

Keterangan gejala :

G01 : Rasa haus meningkat

G02 : Sering buang air kecil

G03 : Nafsu makan bertambah

G04 : Penurunan berat badan

G05 : Kelebihan berat badan

G06 : Berat badan bervariasi

G07 : Gangguan penglihatan

G08 : Kelelahan

G09 : Mudah emosi

G10 : Infeksi kulit

G11 : Gatal-gatal pada kulit

G12 : Riwayat keluarga penderita diabetes

G13 : Depresi

G14 : Kesemutan

G15 : Nafas berbau buah-buahan

G16 : Mengompol

G17 : Proses penyembuhan luka lama/sulit

G18 : Riwayat keluarga penderita diabetes selama kehamilan

G19 : Riwayat diabetes pada kehamilan sebelumnya

G20 : Pernah melahirkan bayi dengan berat $>9$ pounds $(4,5 \mathrm{~kg})$

G21 : Insomnia

G22: Gemetaran

G23 : Berkeringat

G24 : Mudah Gelisah

G25 : Mudah merasa kebingungan

G26 : Mudah rofe

G27 : Suasana hati mudah berubah

G28 : Mual

G29 : Muntah

G30 : Kulit kering

G31 : Sakit dan nyeri

G32 : Sering mengalami infeksi jamur

G33 : Mimpi buruk

G34 : Kejang

G35 : Mudah merasa sedih

G36 : Sering tidak sadar

G37 : Mati rasa

G38 : Infeksi mikotik vagina

G39 : Detak jantung cepat

G40 : Sering mengalami infeksi gusi

G41 : Impotency

G42 : Tekanan darah tinggi

G43 : Mengalami tidur berjalan

G44 : Membuat suara-suara yang tidak biasa

G45 : Keram kaki

G46 : Bicara tidak jelas

G47 : Wajah memerah

G48 : Kulit pucat

G49 : Kehilangan menstruasi 
G50 : Sakit perut

G51 : Napas dalam-dalam

G52 : Area kulit yang gelap

G53 : Konsentrasi yang Sulit

G54 : Dehidrasi

G55 : Kurang koordinasi anggota tubuh

G56 : Riwayat penyakit jantung

G57 : Sindrom ovarium polikistik

G58 : Gula darah rendah pada bayi segera setelah melahirkan

G59 : Ukuran pinggang lebih dari $102 \mathrm{~cm}$ pada pria dan $88 \mathrm{~cm}$ pada wanita

G60 : Rasio pinggang ke pinggul lebih dari 0,9 pada pria dan 0,85 pada wanita

\section{Rule}

Berdasarkan knowledge base pada table 1, maka rule yang diterapkan pada sistem adalah:

1. Rule 1

Jika mengalami penurunan berat badan dan nafas berbau buah-buahan dan mengompol dan mudah lelah dan suasana hati mudah berubah dan mual dan muntah dan kulit tampak pucat, maka hasil diagnosanya adalah diabetes tipe 1 .

\section{Rule 2}

Jika berat badan mudah naik-turun dan proses penyembuhan luka lama/sulit dan kulit kering dan merasa sakit dan nyeri dan sering mengalami infeksi jamur dan detak jantung cepat dan terdapat area kulit yang gelap, maka hasil diagnosanya adalah diabetes tipe 2 .

\section{Rule 3}

Jika mengalami gatal-gatal pada kulit dan memiliki riwayat keluarga penderita diabetes dan mengalami depresi dan mudah kesemutan dan sering mengalami infeksi gusi dan memiliki riwayat penyakit jantung dan mengalamin sindrom ovarium polikistik dan memiliki ukuran pinggang lebih dari $102 \mathrm{~cm}$ pada pria dan $88 \mathrm{~cm}$ pada wanita dan memiliki rasio pinggang ke pinggul lebih dari 0,9 pada pria dan 0,85 pada wanita, maka hasil diagnosanya adalah pre diabetes.

\section{Rule 4}

Jika memiliki riwayat keluarga penderita diabetes selama kehamilan dan memilikin riwayat diabetes pada kehamilan sebelumnya dan pernah melahirkan bayi dengan berat $>9$ pounds $(4,5 \mathrm{~kg})$ dan memiliki tekanan darah tinggi dan kadar gula darah rendah pada bayi segera setelah melahirkan, maka hasil diagnosanya adalah gestational atau diabetes saat kehamilan.

\section{Interface}

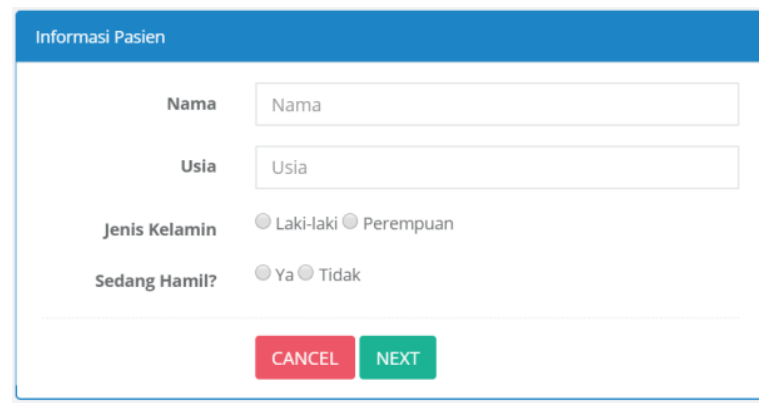

Sumber: (Hardani, 2019)

Gambar 4. Interface Informasi Pasien

Gambar 4 diatas merupakan tampilan awal aplikasi, dimana pengguna diminta untuk menginput data singkat pasien. Pertanyaan "Sedang Hamil" adakan disabled jika jenis kelami adalah laki-laki

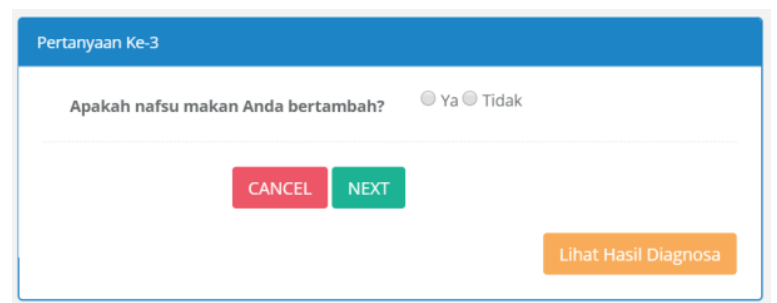

Sumber: (Hardani, 2019)

Gambar 5. Interface Pertanyaan

Keterangan:

Ketika klik tombol "Lihat Hasil Diagnosa"

1. Jika jawaban sudah memenuhi minimal syarat diagnosa, maka akan ditampilkan hasil diagnosa

2. Jika jawaban belum memenuhi minimal syarat diagnosa, maka akan pesan bahwa jawaban belum memenuhi syarat diagnosa

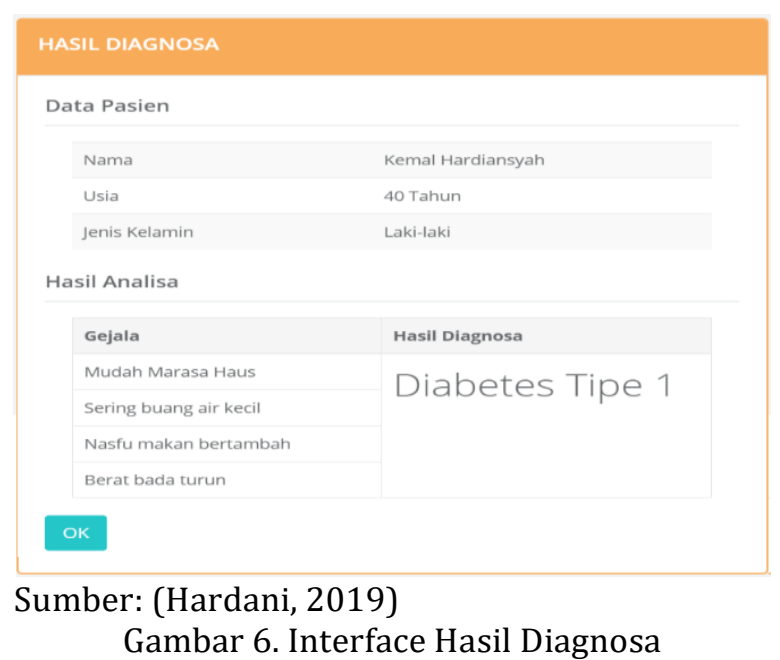


Gambar 6 diatas merupakan hasil diagnosa berdasarkan analisa jawaban pengguna. Dalam halaman hasil diagnosa tersebut ditampilkan data singkat pasien, jawaban pengguna atas pertanyaan yang diberikan, dan hasil diagnosa.

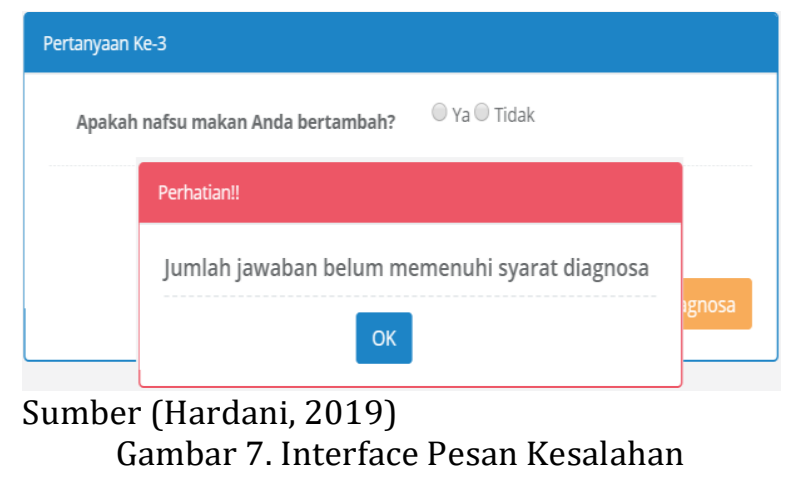

Seperti yang sudah dijelaskan pada alur aplikasi, pengguna dapat menampilkan hasil diagnose tanpa harus menyelesaikan seluruh pertanyaan di aplikasi. Namun jika jawaban belum memenuhi syarat aplikasi, maka aplikasi akan menampilkan pesan seperti gambar 7 diatas, kemudian aplikasi akan menampilkan pertanyaan berikutnya.

\section{KESIMPULAN}

Penerapan inferensi menggunakan Forward Chaining dalam diagnosa penyakit diabetes menjadi pilihan tepat karena proses diawali dengan adanya fakta-fakta yang diterapkan dalam role untuk mencari sebuah kesimpulan. Dengan adanya aplikasi sistem pakar untuk mendiagnosa penyakit diabetes, diharapkan pasien dapat mendiagnosa sendiri penyakit diabetes berdasarkan gejala yang dialami. Dengan mengetahui lebih dini, pasien dapat mengambil tidakan yang dibutuhkan untuk melakukan pengobatan atau pengendalian melalui perubahan gaya hidup dan pola makan.

\section{REFERENSI}

Bansal, N. (2015). Prediabetes diagnosis and treatment: A review. World Journal of Diabetes, 6(2), 296-303. https://doi.org/10.4239/wjd.v6.i2.296

Cho, N. H., Shaw, J. E., Karuranga, S., Huang, Y., Rocha, J. D., Ohlrogge, A. W., \& Malanda, B. (2018). IDF Diabetes Atlas : Global estimates of diabetes prevalence for 2017 and projections for 2045. Diabetes Research and Clinical Practice, 138, 271-281. https://doi.org/10.1016/j.diabres.2018.02.0 23

Choubey, D. K., \& Paul, S. (2017). Rule based diagnosis system for diabetes, (January).

Hardani, S. (2019). Laporan Akhir Penelitian Sistem Pendukung Keputusan Diagnosa Diabetes. Jakarta: Jakarta.

Kementrian Kesehatan. (2014). Situasi dan Analisis Diabetes. Pusat Data Dan Informasi Kementrian Kesehatan RI, (Diabetes).

Rupnawar, A., Jagdale, A., \& Navsupe, S. (2016). Study on Forward Chaining and Reverse Chaining in Expert System. International Journal of Advanced Engineering Research and Science, 3(12), 60-62. https://doi.org/10.22161/ijaers/3.12.12

Salisah, F. N., Lidya, L., \& Defit, S. (2015). SISTEM PAKAR PENENTUAN BAKAT ANAK DENGAN MENGGUNAKAN METODE FORWARD CHAINING. Jurnal Ilmiah Rekayasa Dan Manajemen Sistem Informasi, 1(1), 62-66.

Makan Dengan Kadar Gula Darah Pada Penderita Diabetes Mellitus. Jurnal Kesehatan Vokasional, 3(1), 29-34. Retrieved from https://journal.ugm.ac.id/jkesvo/article/vie $\mathrm{w} / 34080$

Zeki, T. S., Malakooti, M. V, Ataeipoor, Y., \& Tabibi, T. (2012). An Expert System for Diabetes Diagnosis. American Academic \& Scholarly Research Journal, 4(5), 1-13. Retrieved from http://www.aasrc.org/aasrj/index.php/aasrj /article/view/581 